\title{
The pedagogy of design and technology at Xavier University of Louisiana, New Orleans
}

\author{
Shayna T. Blum \\ Xavier University of Louisiana, New Orleans, LA, USA
}

\begin{abstract}
Xavier University of Louisiana (XULA) is a Science, Technology, Engineering, and Mathematics (STEM) university located in New Orleans, Louisiana. As an Historically Black University (HBCU), the university serves a diverse community of students in which many are first generation college graduates. Students enrolled in Design courses at XULA are studying in Bachelor of Science and Bachelor of Art programs and majoring in subjects such as Computer Science, Physics, Mass Communication, Art, Business, and Science. The interdisciplinary student environment offers a unique opportunity for collaboration and peer learning, whereby students are able to share diverse perspectives on a topic by relating design processes to their fields of study. In laboratory practice, students work on independent and collaborative projects in Product Design and User Experience by developing work through a design process from ideation to production. Keywords. Design, Technology, UX, Pedagogy, Visual Communication
\end{abstract}

\section{Introduction}

The purpose of the article is to inform the reader about the experience of teaching design and technology at Xavier University of Louisiana (XULA) by focusing on the methods by which the subject is taught to a diverse and interdisciplinary undergraduate student demographic. The article will review the context in which the design curriculum at XULA has been developed. Methods of research for the article include a literature review of academic articles on the pedagogy of design, design thinking, design theory, product design, and user experience design. The resources used for locating articles included the XULA library database, Google Scholar, JSTOR, Academia EDU, and Google News. In addition, a range of digital artifacts were collected, including photographs, project reports, and student evaluations.

The article will examine the advances currently taking place in the fields of design and technology across global society and review the creative skills that students are taught in order to prepare them for a professional career in this context. Concentrating on projects from the Graphic Design and Advertising and the Web Design and Development courses during the 2018-2019 academic year, the article reviews the pedagogy of design at XULA by examining two collaborative projects in user experience (UX) and product design. The article reviews student processes, experiences, challenges, and outcomes.

\section{Xavier University of Louisiana}

XULA is a STEM-focused university located in New Orleans, Louisiana. As an Historically Black University (HBCU), the university serves a diverse community of students in which many are first generation college attendees. The mission of XULA is to contribute to the promotion of a more just and humane society by preparing its students to assume roles of leadership and service in a global society [1]. The total number of students enrolled at XULA in the Fall of 2018 was 3,231 , of which 2,293 were undergraduates studying in the College of Pharmacy or the College of Arts and Science [2]. According to the XULA website, 69.7 percent of its enrolled students are African American while 39.3 percent are a mix of national and international students [3]. The gender distribution of students is 27 percent male and 73 percent female, and more than one half of XULA students are from Louisiana (55.6 percent), primarily from the New Orleans area $[4,5]$.

The ART 2020, 4010 Graphic Design and Advertising, and the ART 3020 Web Design and Development courses are designed as interdisciplinary, hybrid courses in which students engage in active peer 
learning during seminars and studio practice. Classes meet weekly to discuss materials and projects, and students independently form their own schedule for studio practice. During the 2018-2019 academic year, ART 2020 and ART 4010 Graphic Design and Advertising had a total number of 34 students within four sections, across which the number of female students (20) was higher than the number of male students (14) [6, 7]. The disciplines in which students were majoring varied: Computer Science and Engineering/Physics had the highest number of students (14); Mass Communication was second (11), followed by Biology and Chemistry Pre-med (5), Business (3), and Art (2) [8]. ART 3020 Web Design and Development had a total of 23 students within three separate sections. Out of the 23 students, 20 were female and 3 were male, and the student majors varied: Psychology and Neuroscience had the highest number of students (6), followed by Chemistry and Pre- pharmacy (4). Biology/Pre-med, Mass Communication, and Art tied with 3 students from each major, and Computer Science and Public Health tied with 2 students from each major [9].

The design laboratory in which courses are taught is approximately $25^{\prime}$ x $12^{\prime}$, with walls lined with painted cork board so that students can use the space to hang notes and sketches created during the ideation phase of projects. When entering the lab, a large table is located on the left which is positioned for viewing the large projector used for lectures and student presentations. The lab is equipped with 16 MAC computers installed with Adobe Creative Suite and Microsoft Office. Challenges the we have experienced in facilities and lab technology include budget and resource limitations, difficulty in keeping up-to-date with field standard products and software, unpredictable internet connections, and no studio printing and scanning options.

As a professor of design and technology, teaching within a discipline-diverse student landscape, I prefer to take advantage of opportunities for students to work collaboratively to integrate their knowledge and perspectives on varying ideas. My objective is to equip students with the creative skills needed for professional life within the current global market. Course goals include enhancement of student capabilities in identifying and problem-solving through form building and design. For project assignments, students are given a brief in which the project requirements are described. Students are asked to follow the brief throughout the design process and to begin their work throughresearch analysis. The information is discussed and organized in brainstorming sessions where students visualize their ideas by organizing data, mind mapping, and sketching. Throughout the course of the semester, students are assessed on verbal, written, and visual communications, including class discussions, critiques, presentations, reading summaries, typed project reports, printed designs, and multimedia presentations created in PowerPoint and/or Google Slides.

Introduced to courses in fall of 2018, GroupMe (group texting) has been adapted as a tool for communication and peer learning. Using their personal devices, students share materials such as photographs of notes taken in class, images of project development, and video and audio recordings of lectures and demonstrations. The platform is an excellent tool for students to assist each other with questions involving class and assignments and helps to keep student attendance and participation high due to the ease of text reminders.

\section{Design}

Design is the formation of a product through a problemsolving process in which the user/market experience with the product is the primary focus of the design solution. Writer Elzbieta T. Kazmierczak defines design as the "activity that directs the process and enables a correspondence" between a sender and a receiver [10]. She explains that, through the growth in technology and global interactivity, a shift is currently taking place in which the creative design process has evolved from a focus on forming a physical solution to a focus on the "cognitive processes" that occur within the design process [11]. In this context, the term 'design' references the 'processes' through which a need and/or challenge is identified, and a solution is formed through exploration, problem-solving and strategizing. The outcome is presented in physical and/or non-physical contexts such as a brand, service, machine, campaign, or virtual reality (VR).

Theorists Rim Razzouk and Valerie Shute define design as a creative thinking process in which the maker has the capabilities and skills to engage in opportunities of brainstorming, experimenting, prototyping, discussing feedback, and redesigning based on response [12]. (Image. 1) They believe that in today's "highly technological and globally competitive world" a person requires design thinking skills to be successful in most professions [13]. Originating in the fields of visual communication, architecture, and design, design thinking has historically been the creative process by which makers/authors have developed a product intended for a receiver/audience. Writer Thomas Fisher describes design thinking as the "creative process [in] which designers generate new ideas... and [is] the critical process of assessing to arrive at optimal solutions to complex problems" [14]. He continues, "Design thinking generates creative ideas and actionable solutions in ways that no other type of thinking can" [15]. Fisher associates design thinking processes with the traditional design disciplines: graphic design; apparel design; product design; interior design; architecture; landscape architecture; and urban design and planning [16]. However, the design thinking process is currently being incorporated into alternative fields of 
study such as science, education, business, psychology, geography, and economics $[17,18]$.

Design thinking has had a positive impact on 21 stcentury education across many disciplines, creating an academic environment that offers students the opportunity to develop creative thinking skills by engaging in explorative, experimental, and collaborative projects. Razzouk and Shute state that "to help students succeed in this interconnected, digital world we live in, educators should support students in developing and honing 21st-century skills (e.g., design thinking, systems thinking, and teamwork skills)" [20].

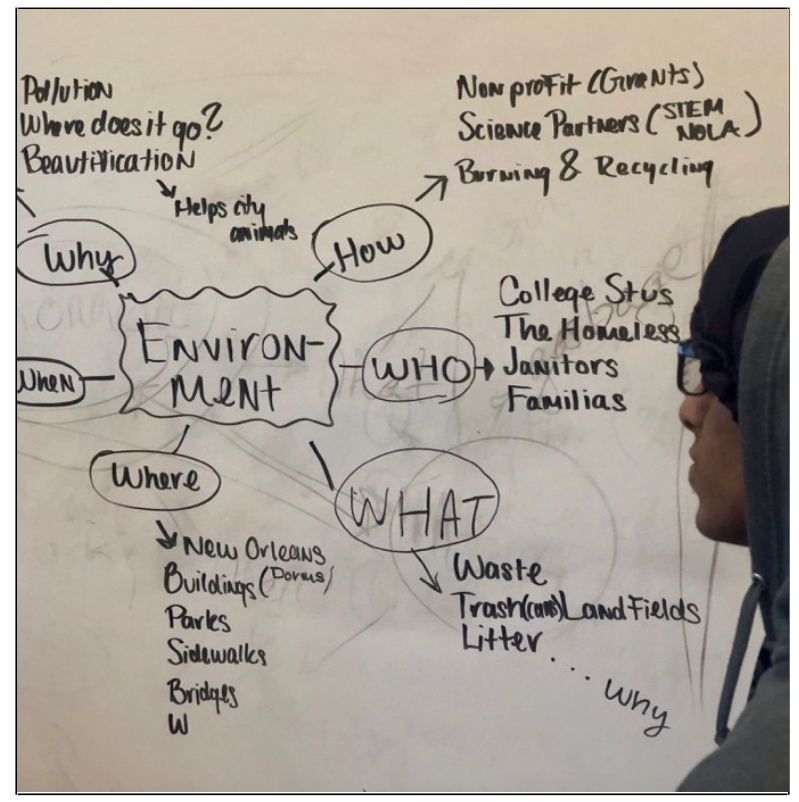

Image. 1. Design Thinking: brainstorm mind mapping.

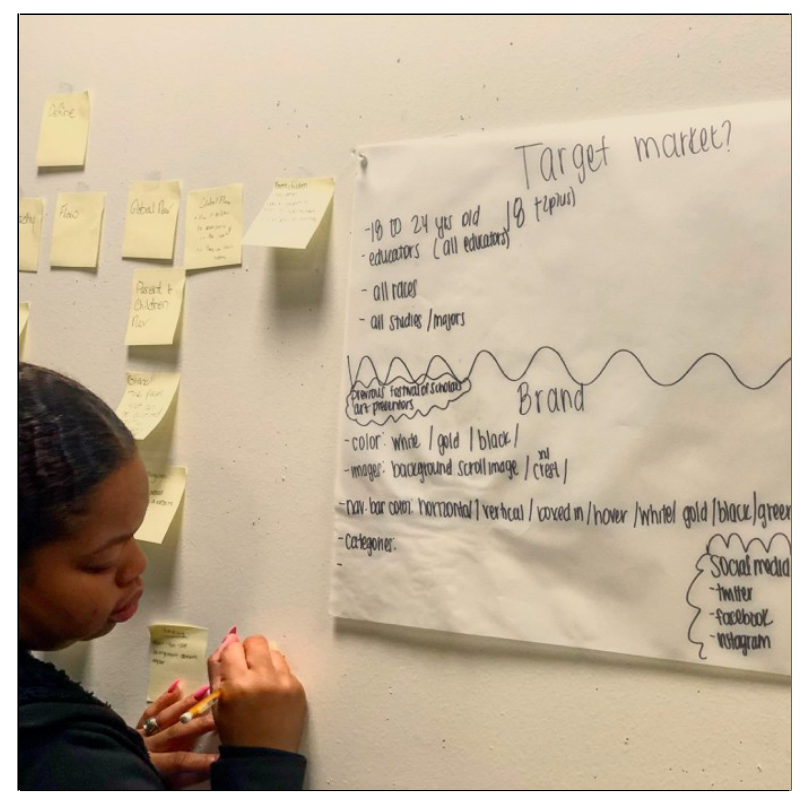

Image. 2. Design Thinking: target user/market.

According to Razzouk and Shute, the traits of a creative thinker lead to a unique approach towards problem-solving and strategizing. They list characteristics that they believe a design thinker should possess: ability to visualize; capability to multitask and work systematically; ability to communicate effectively in visual, verbal and written form; interest in, and ability to participate in, teamwork; and ability to think innovatively [21]. For students to develop such skills, faculty would benefit from refocusing teaching methods away from the standard classroom pedagogy to an interactive learning environment in which students engage in teamwork through exploratory assignments. As Razzouk and Shute explain, "our goal as educators should not focus on preparing our students to perform well on standardized exams, but [to] equip them with powerful skillsets that can help them succeed both within and outside of school.... teaching students to think like designers may better prepare them to deal with difficult situations and to solve complex problems in school, in their careers, and in life in general" [22].

\section{Design @ XULA}

The design process, which a designer experience in building a product, is a non-linear creative practice that can be categorized into different phases and roles [23]. Design research describes the initial phase of the project, in which challenges are identified and analyzed using qualitative and quantitative research methods including literature reviews, market surveys and interviews, brainstorming, visualization, and experimentation. Visualization is the process by which the designer explores ideas through sketches and/or digital diagrams. On receiving feedback from the design team, the visualization of the product will progress to the production to the design prototype. Once complete, the product will be tested, surveyed, and evaluated again. After this, feedback from users and teams will be considered to improve the work and develop the final design. After the final design is finished, the project is launched to a public market/audience/user and is evaluated by the research and design team based on user response and feedback. (Image. 2) Product evolution and growth in value depends on the perceptions and experiences of the market when interacting with the product. Therefore, the product's relationship with the user/market is continuously examined and adjusted based on research and user feedback [24].

Current developments in design and visual communication concentrate on the perception of users when the user is interacting with a product [25]. Since the shift from the modern into the post-postmodern era, four factors have contributed to the study and process of design: technological advancement; a rise in product/service production and marketing; design research growth; and collaboration from interdisciplinary fields [23]. Design processes and outcomes have evolved from advances in technology and visual devices and have resulted in a need for creative methods of presenting content to an audience. Current design processes center on the user's 
needs/desires, identity, and experiences, and require innovative solutions in product and service design through interdisciplinary studies in aesthetics, science/technology, psychology, and sociology [26].

In the ART 2020, 4010 Graphic Design and Advertising and the ART 3020 Web Design and Development courses at Xavier University of Louisiana, students focus on design thinking and the design process from ideation to production. They form solutions for products, services, brands, and experiential design. Each phase of the design process is assigned a deadline and the students meet as a class to critique and discuss progress and receive feedback from their peers. The final work is shared as a formal presentation where the students outline their process of research, brainstorming, problem-solving/strategizing, hand sketching, and producing the final product. In addition to the presentation, students submit a typed project report in hard and soft copy detailing their design process and outcome.

\subsection{Project: Examples}

\subsubsection{User Experience Design}

User experience design (UX) and user-centered design focus on the relationship and interactivity between a product and the user's experience of the product. The goal of user experience design is to stimulate a positive emotional response in the user in order to form a positive perspective on and memory of the product. In their article, "Design-inclusive UX research: design as a part of doing user experience research", Arnold P.O.S. Vermeeren, Virpi Roto, Kaisa Väänänen state, "Designing for UX requires looking for design opportunities that may affect people's emotions in a positive way. This requires empathy and design skills from the designer and creates new challenges" [27]. In the Web Design and Development course, students explored the subject of user experience and humancomputer interaction (HCI) and the ways in which a user interacts with and experiences a screen-based device. The user experience project was assigned to offer students an opportunity to work collaboratively when investigating UX design processes.

For the project students were asked to analyze an existing company website and formulate ideas for better design. Teams comprised four students and each was assigned a role. In phase one of the assignment students interacted with and analyzed a website or application of their choosing. Student 1 selected a website or application from the internet and recorded notes describing the website brand and interface. Student 1 then presented the site (from the index page) to student 2 who visited the site and interacted with the product. Student 3 sat behind student 2 and video-recorded student 2's interaction with the site via cursor movement and navigation (for a total of three minutes). Student 4 faced student 2 to video-record facial expressions during these three minutes. Once the recording was complete, students 1,3 , and 4 interviewed student 2 about her experience with the product. (Image 3.)

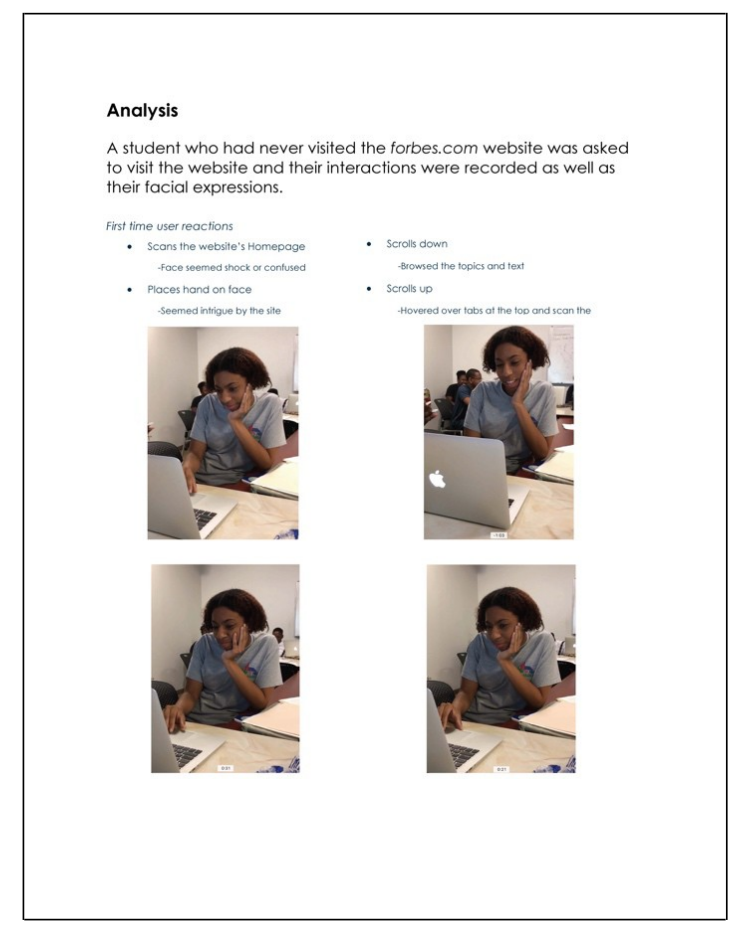

Image. 3. UX Project: student observation \& analysis.

Having collected this information, students were asked to organize and list observations about student 2's interaction with the website or application. The team then drew out a wireframe on grid paper to sketch the layout of a page by locating the header, navigation, content, and footer. On the wireframe(s), students located areas of interest by comparing video frames to analyze the user's interaction and experience with the website. The points of observation were labeled on the wireframe with notes from the students' evaluation located in the margins on the sides of the page. After completing the first stage of the project, students gathered all data and brainstormed ideas for producing a better product through layout/organization, navigation, information flow, accessibility typography, and image.

The students sketched sitemap options by hand to present ideas for the global navigation, child navigation, external links, email, and sign in, and finalized the design digitally using either Microsoft Word, Google Docs, Illustrator, or another program of their choosing. (Image. 4) Having completed the sitemap, students developed wireframes for three different pages in which one page was the site index page. The layout of the wireframes included the header, navigation, content, text and image, footer, and functions. The wireframes were first drawn on grid paper with a ruler and pencil and later transferred to the computer to finalize the work in a digital format. Students were instructed to label areas of the sitemap using the Arial font and to show 
information hierarchy through type size. Students indicated a visual media area by placing a box with an ' $x$ ' extending to each corner. (Image. 5, 6)

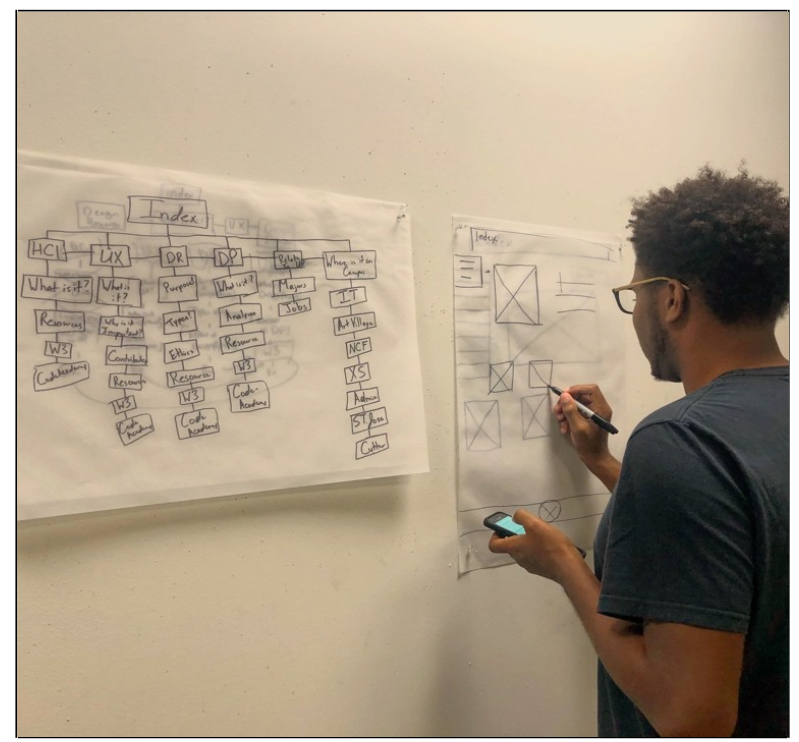

Image. 4. UX Project: sitemap, sketching

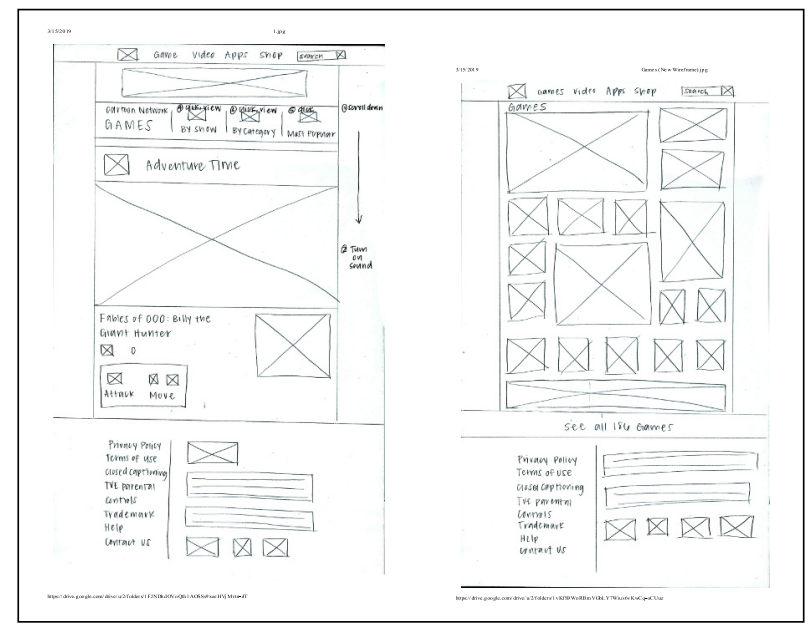

Image. 5. UX Project: student wireframe interaction.

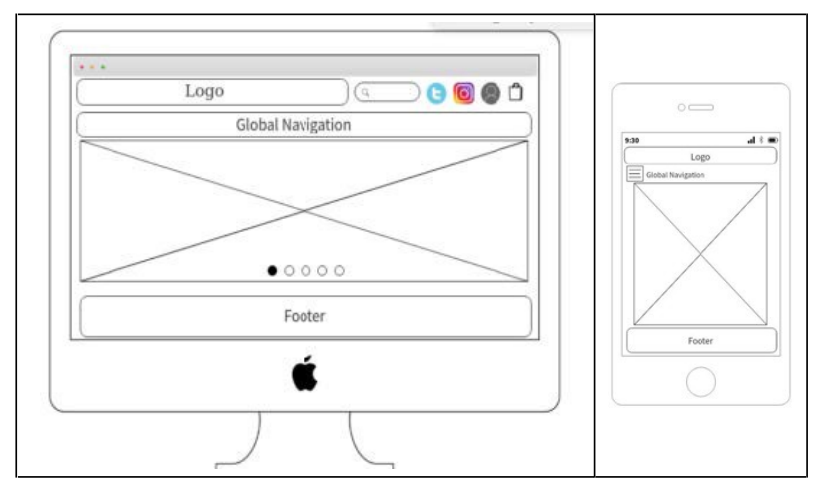

Image. 6. UX Project: digital wireframes, desktop \& mobile.

At the end of the project students presented their research to peers using PowerPoint or Google Slides and submitted a soft and hard copy report. In the final report, students included: a summary of the project brief; a definition of (and brief background information on) user experience; students' experience of visiting sites; digital artifacts from the experiment' the discovery process (i.e., brainstorm/mind map, sketches)' description of analysis; challenges and problem solving; strategy; final outcome; sitemap; and wireframes. Projects were assessed based on participation, team performance, research and analysis, conceptual development, design elements (i.e., type, color, layout, technology) verbal and written communication, and final presentation.

\subsubsection{Product Design}

The city of New Orleans was originally built on swamp land along the Mississippi River, near the Gulf of Mexico. Due to the city's location, New Orleans is prone to tropical storms and hurricanes, during which the intense weather and the characteristics of the natural environment lead to extensive flooding throughout the city. The flooding contributes to additional complications such as unhealthy water, boiler alerts, urban damage, and economic insecurity. In the Graphic Design and Advertising course, students were assigned a product design and experiential marketing project as a final project. By working collaboratively students were to utilize interdisciplinary perspectives to design a product as an innovative solution to solve the city's flooding problem. The project was designed in multiple parts, through which students were to examine elements of environmental design, urban design, product design, branding, and experiential marketing.

Intended to be 2 teams of 4 students, due to missing students on assignment day the project became 1 team of 7 students. Students did not receive a budget for the project and therefore there was no limitation on ideas and cost. Initially, the team researched the location and environment of New Orleans and examined alreadyestablished products and methods used by the city to maintain water conditions. Students then investigated technologies and materials used by global locations with similar environmental issues to New Orleans. Once this process was complete, students moved into two groups to divide up work. One group organized notes and artifacts collected during the research stage. Their role was to organize information using mind mapping diagrams, content outlines, and digital graphs and charts created in Google Sheets or Excel. The second group worked on the visualization and aesthetic form of the product by sketching ideas by hand and digitalizing the work in Illustrator.

The team designed Streamline: "a company with plans to build an extensive pipeline that will pump excess water from New Orleans to other cities that are in need of water because of drought. This will be done through adding hydroelectric dams to the New Orleans levees. The power from those dams during times of flood risk will turn on pumps that will pull water into 


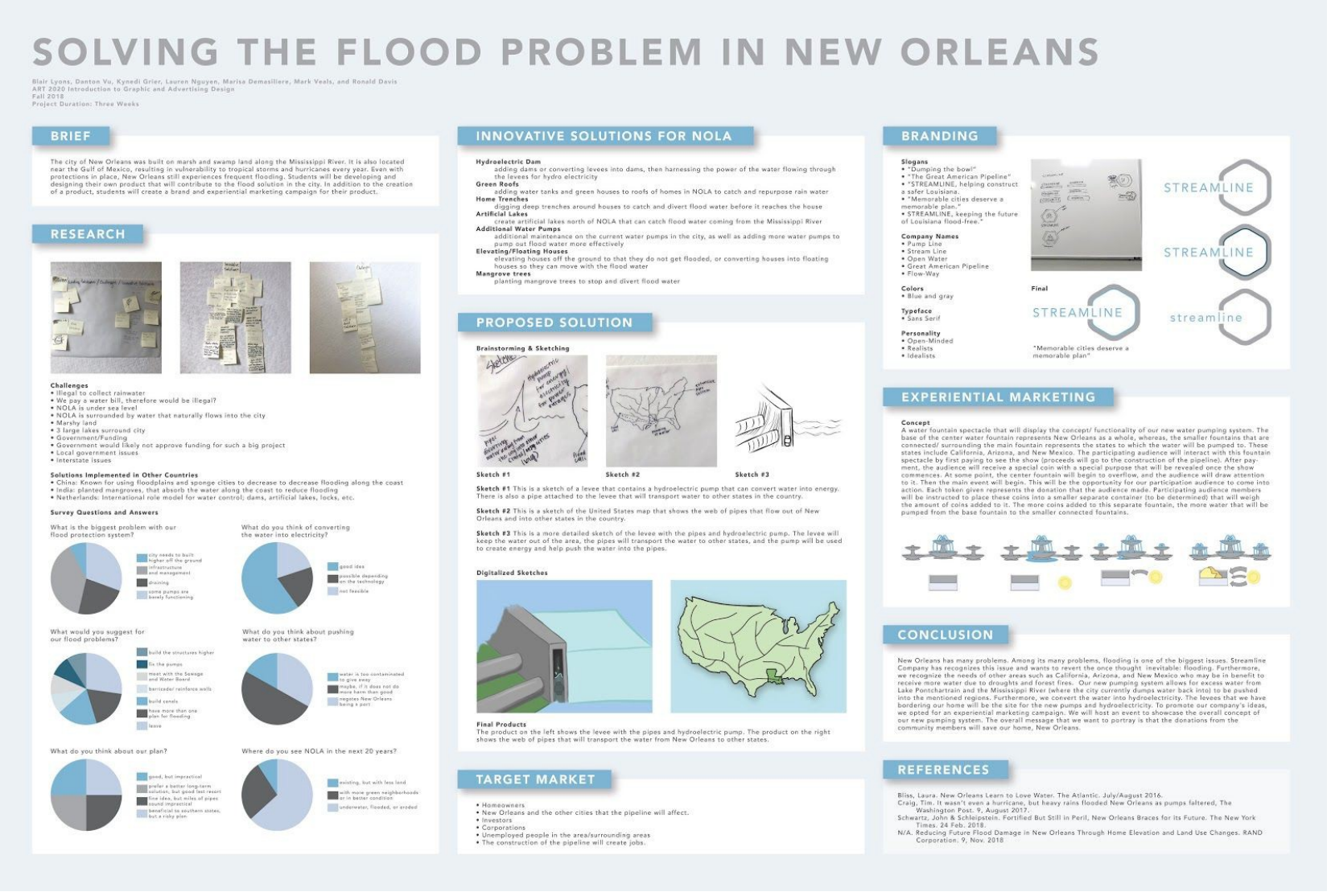

Image. 7. Product Design: research \& process poster.

\section{Conclusion}

For the User Experience and Product Design projects, students were graded as a team on organization and performance, research and writing, problem-solving and conceptualizing, and visual presentation and communication. Individually, they were graded on participation and engagement. Students stated they enjoyed the projects and liked working collaboratively. However, problems did occur with students not showing up for studio and not doing the work asked of them. Team members were concerned about having to take on extra work and/or losing points on their grades. Currently, the faculty are reviewing the project rubrics and will make adjustments based on these observations from the 2018-2019 academic year. In addition, the faculty seek to improve the tracking of group performance and participation via project surveys, feedback, and team evaluations.
The diverse and interdisciplinary learning environment offered for Design \& Technology courses

at Xavier University of Louisiana allows for a unique opportunity to develop collaborative projects in which students engage in the design process and develop skills in creative thinking and practice. The faculty will continue to explore possibilities for student participation in active and peer learning within seminar and laboratory design courses. In the 2018-2019 academic year, two new design and technology seminar courses (XCOR 3010 Design and Technology in GlobalCulture and XCOR 1012 New Orleans Innovation Bootcamp) were added to the XULA core curriculum. Both courses are being taught this semester (Spring 2019), and the faculty are gathering data on student performance and course progression. Recently, two new design and technology courses have been submitted to the academic council, and the faculty continue to propose ideas for new courses and programs. Future research will continue to explore concepts in design pedagogy by examining student development in creative skills via interdisciplinary, interactive, and collaborative learning environments. 
4. US News Best Colleges https://www.usnews.com/best-colleges/xavieruniversity-of-louisiana-2032/student-life 5. https://www.xula.edu/factsandfigures 6. S. Blum, [Study in the student demographic of design courses at XULA]. Unpublished Raw data. (2019). 7. S. Blum, [Study in the student demographic of design courses at XULA]. Unpublished Raw data. (2019). 8. S. Blum, [Study in the student demographic of design courses at XULA]. Unpublished Raw data. (2019). 9. S. Blum, [Study in the student demographic of design courses at XULA]. Unpublished Raw data. (2019). 10. E. T. Kazmierczak, Des. Issues 19, 45-59 (2003) 45 11. E. T. Kazmierczak, Des. Issues 19, 45-59 (2003) 46 12. R. Razzouk and V. Shute, Rev. Educ. Res. 82, 330 (2012)

13. R. Razzouk and V. Shute, Rev. Educ. Res. 82, 330 (2012)

14. T. Fisher, Designing Our Way to a Better World (University of Minnesota Press, 2016)

15. T. Fisher, Designing Our Way to a Better World (University of Minnesota Press, 2016)

16. T. Fisher, Designing Our Way to a Better World (University of Minnesota Press, 2016)

17. R. Razzouk and V. Shute, Rev. Educ. Res. 82, 331 (2012)

18. B. Wylant, Des. Issues 24, 3-14 (2008) 5

19. R. Razzouk and V. Shute, Rev. Educ. Res. 82, 331 (2012)

20. R. Razzouk and V. Shute, Rev. Educ. Res. 82, 331 (2012)

21. R. Razzouk and V. Shute, Rev. Educ. Res. 82, 336 (2012)

22. R. Razzouk and V. Shute, Rev. Educ. Res. 82, 336 (2012)

23. S. Blum, UX/UI: Seeing, Interacting, and Experiencing (2017). Unpublished Manuscript. Xavier University of Louisiana

24. S. Blum, UX/UI: Seeing, Interacting, and Experiencing (2017). Unpublished Manuscript. Xavier University of Louisiana

25. S. Blum, UX/UI: Seeing, Interacting, and Experiencing (2017). Unpublished Manuscript. Xavier University of Louisiana

26. S. Blum, UX/UI: Seeing, Interacting, and Experiencing (2017). Unpublished Manuscript. Xavier University of Louisiana

27. C. Svabo and M. Shanks in P. Benz (ed.), Experience Design: Concepts and Case Studies, 23-32 (Bloomsbury Academic, London, 2015) 25

28. A. P. O. S. Vermeeren, V. Roto, and K. Vaananen, Behave. Inform. Technol. 35, 21-37 (2016)

References

R. Arnheim, Visual Thinking (University of California Press, Berkeley, 1969)

P. Benz (ed.), Experience Design: Concepts and Case Studies (Bloomsbury Academic, London, 2015)

T. Fisher, Designing Our Way to a Better World (University of Minnesota Press, 2016) (https://www.jstor.org/stable/10.5749/j.ctt1c0gm71.9) (2017)

E. Gordon, C.A. Bigelow, J. Vision 11, 1-22 (2011)

M. Hassenzahl, User Experience and Experience Design (http://www.interaction-

design.org/encyclopedia/user_experience_and_experie nce_design.html) (2017)

E. T. Kazmierczak, Des. Issues 19, 45-59 (2003), (https://www.jstor.org/stable/23260048, Accessed: 2602-2019 21:22 UTC)

R. Razzouk and V. Shute, Rev. Educ. Res. 82, 330-348 (2012) (https://www.jstor.org/stable/23260048, Accessed: 26-02-2019 21:22 UTC)

L. Vizard, Technology and the Evolution of the Designer's Role, Adobe Blog (https://theblog.adobe.com/technology-and-theevolution-of-the-designers-role/)

A. P. O. S. Vermeeren, V. Roto, and K. Vaananen, Behave. Inform. Technol. 35, 21-37 (2016) (http://dx.doi.org/10.1080/0144929X.1081292)

B. Wylant, Des. Issues 24, 3-14 (2008) (https://www.jstor.org/stable/25224163, Accessed: 2602-2019 21:28 UTC) 